\title{
Comentario de la STS de 11 de diciembre de 2020 (Ro 416/2018, Sala de lo Social) ¿Una doctrina legal en vías de extinción?
}

\author{
Analysis of the STS 11 th December 2020 \\ (Ro 416/2018, Social Court). \\ An extinted case law?
}

Elena Pérez Pérez

Doctora en Derecho

Universidad de Cantabria

ORCID ID: 0000-0003-0898-1213

Recibido: 20/1/2021

Aceptado: 4/5/2021

doi: https://doi.org/10.20318/labos.2021.6220

Resumen: La sentencia del Tribunal Supremo comentada analiza la problemática jurídicolaboral derivada de las operaciones de venta de empresas en situación de concurso. La premisa central es que el legislador español ha optado por la aplicación de las garantías de la sucesión de empresa en supuestos de insolvencia empresarial. A partir de ello, se rechaza la extensión de los efectos de la resolución que dicta el juez mercantil y se aplica la responsabilidad solidaria derivada de contratos ya extinguidos. El análisis se realiza a través de las disposiciones legales de la Ley Concursal 22/2003, de 9 de julio.

Palabras clave: sucesión de empresa, empresa en concurso

Abstract: $\quad$ The commented ruling of the High Social Court analyzes the legal-labour problems derived from the sale of companies in a situation of insolvency. The central premise is that the Spanish legislator has opted for the application of guarantees of transfer of undertaking in cases of business insolvency. On that basis, the extension of the effects of the decision issued by the comercial judge is rejected and joint and several liability derived from contracts that have already been terminated is applied. The study is carried out through the existing legal provision of the text of the Bankruptcy Law 22/2003, of 9 July.

Keywords: $\quad$ transfer of undertaking, bankrupt company 


\section{Cuestión de fondo}

\subsection{Supuesto de hecho}

La sentencia objeto de comentario analiza el despido objetivo de una trabajadora, que acciona tanto frente a su empleadora como frente a la adjudicataria de la unidad productiva en la que prestaba servicios, interesando la responsabilidad solidaria de la misma, en su calidad de sucesora.

La empresa fue declarada en concurso el 20 de noviembre de 2014 y la trabajadora fue despedida, con efectos a fecha de 26 de octubre de 2014.

El 29 de julio de 2015 el juez del concurso adjudicó a la empresa codemandada la unidad productiva en la que había prestado servicios la demandante, declarando que no constituía una sucesión empresarial. Dicha resolución adquirió firmeza.

La sentencia recurrida declara que se produjo una sucesión empresarial e impone la responsabilidad solidaria a la nueva adjudicataria, aun cuando la relación laboral se había extinguido antes de la adquisición.

\subsection{Cuestiones objeto de debate}

En el recurso de casación se plantean dos motivos.

En el primero de ellos, se denuncia la infracción de los artículos 146 bis, 148 y 149 de la Ley Concursal ${ }^{1} y$ de los artículos 3, 4 y 5 de la Directiva 2001/23, del Consejo, de 12 de marzo de 2001, sobre la aproximación de las legislaciones de los Estados miembros relativas al mantenimiento de los derechos de los trabajadores en caso de traspasos de empresas, de centros de actividad o de partes de empresas o de centros de actividad ${ }^{2}$.

Como sentencia contradictoria se cita la STSJ de Cataluña, de 19 de febrero de 2016 (Ro 3271/2015). En la misma se considera que no es posible aplicar el artículo 44 del Estatuto de los Trabajadores ${ }^{3}$-en adelante, ET- cuando el juez del concurso fija en el auto de adjudicación de la unidad productiva que no se produce sucesión de empresa.

El segundo motivo es una mera reiteración del primero. Se invoca, de nuevo, el artículo 44 ET y se aduce como sentencia contradictoria la STSJ de Madrid, de 16 de junio de 2017 (Ro 339/2017), que establece que los efectos de la sucesión de empresa declarada por el juez del concurso al tiempo de la adjudicación de la unidad productiva deben proyectarse sobre el orden social.

\section{Doctrina aplicable}

La doctrina aplicable al caso puede resumirse del modo siguiente.

En primer lugar, se parte de que el artículo 44 ET regula la adjudicación de una unidad productiva que tiene lugar en sede del procedimiento concursal, en concreto, en la fase de liquidación, con independencia de lo que se haya resuelto el juez mercantil en el auto de adjudicación. De este modo, cuando la adjudicación de la unidad productiva suponga un cambio de titularidad de una entidad que mantiene su identidad, será aplicable la citada norma de derecho imperativo.

\footnotetext{
${ }^{1}$ Ley 22/2003, de 9 de julio, Concursal. BOE núm. 164, de 10 de julio de 2003.

${ }^{2} \mathrm{~L}$ 82/16, de 22 de marzo de 2001.

${ }^{3}$ Real Decreto Legislativo 1/1995, de 24 de marzo, por el que se aprueba el texto refundido de la Ley del Estatuto de los Trabajadores. BOE núm. 75, de 29 de marzo de 1995, que era la normativa vigente en el momento de los hechos analizados en la sentencia.
} 
Por otro lado, se argumenta que el artículo 148.4 LC no excluye la aplicación del artículo 44 ET, sino que, por el contrario, la admite de forma implícita, al remitir al procedimiento del artículo 64 LC la tramitación de las medidas colectivas de extinción, suspensión, modificación sustancial de condiciones de trabajo o traslados. Además, en cualquier caso, las adquisiciones en sede concursal están sujetas a las normas de derecho imperativo del ordenamiento jurídico.

De otra parte, se analiza la normativa europea sobre la materia, en concreto, el artículo 5 de la Directiva 2001/23. La misma establece una norma general de no aplicación de las garantías de la sucesión de empresa a los supuestos concursales. Pero, a su vez, el precepto tiene una excepción para el caso de que la normativa del Estado Miembro contenga una disposición en contrario. Es lo que ocurre en el caso espańol con el artículo 148.4 LC, que alude expresamente a la sucesión de empresa y con el artículo 149.4 $\mathrm{LC}^{4}$, que permite que el juez del concurso limite la responsabilidad del adquirente de la unidad productiva, pero solo respecto a las obligaciones cubiertas por el FOGASA.

\section{Resolución}

Partiendo de la referida doctrina, el Tribunal Supremo resuelve la controversia declarando la existencia de sucesión, dado que en el caso se produjo una venta de una unidad productiva que reúne los requisitos del artículo $44 \mathrm{ET}$. Esto es, se asumieron un conjunto de medios organizados que permiten llevar a cabo una actividad económica.

La consecuencia de este pronunciamiento inicial es que la referida operación lleva aparejadas las obligaciones y garantías del citado artículo 44 ET. Dentro de ellas se incluyen las propias de la calificación del despido, pues el artículo 44 ET impone la responsabilidad solidaria durante tres años y ello incluye los créditos de los trabajadores de la empresa concursada, incluso los procedentes de contratos ya extinguidos al tiempo de la sucesión.

Además de lo anterior, se puntualiza que el previo pronunciamiento firme del juez del concurso negando la existencia de sucesión, no produce efectos de cosa juzgada frente a los trabajadores individuales, dado que estos no han podido personarse en el procedimiento concursal y, por tanto, tampoco han podido impugnar dicha resolución judicial.

Estos razonamientos sirven para dar respuesta a los dos motivos de recurso formulados, dado que ambos versan sobre la misma cuestión.

\section{Opinión crítica}

La sentencia objeto de comentario aborda los efectos que derivan de la venta de una unidad productiva perteneciente a una empresa en situación de concurso. El análisis parte del articulado de la anterior LC, que es la normativa aplicable al caso.

Se trata de una materia que es ciertamente compleja, ya que, de una parte, la operación de venta, generalmente, es una necesidad empresarial de cara a garantizar la continuidad de la empresa en el mercado ${ }^{5}$. Esta operación está sometida al régimen de autorización del juez del

\footnotetext{
${ }^{4} \mathrm{La}$ actual regulación se encuentra ahora en el artículo 224 TRLC.

${ }^{5}$ La legislación concursal, durante la fase de concurso, no solo atiende a la satisfacción de los créditos de los acreedores y a la conservación del patrimonio, sino también al mantenimiento de la actividad de la empresa. Vid., en este sentido, GONZÁLEZ BILBAO, E., "Identificación de los “intereses concurrentes” y del “interés del concurso" en la nueva Ley concursal”, en AAVV, Estudios sobre la Ley concursal: libro homenaje a Manuel Olivenza, Vol. 1 (Escritos sobre don Manuel Olivenza Ruiz, derecho concursal, aspectos generales, antecedentes históricos, derecho comparado, derecho uniforme, derecho europeo, derecho internacional privado, la declaración de concurso), Vol I, Madrid, Marcial Pons, 2005, ISBN 84-9768-178-9, pp. 293-314. Los mismos intereses están presentes en la fase
} 
concurso $^{6}$, lo que es lógico, dados los especiales intereses del procedimiento concursal ${ }^{7}$. Ahora bien, la complejidad del tema surge porque las competencias que ostenta el juez concursal no se limitan a la autorización o denegación de la venta, sino que se extienden a un ámbito mucho más amplio, que comprende la delimitación de la responsabilidad por deudas pendientes de la empresa concursada.

Hay que tener en cuenta que la operación traslativa puede reunir los requisitos que son propios de la institución laboral de la sucesión de empresa. Por ello, la delimitación de este concreto ámbito de responsabilidad tiene una relevancia fundamental dentro del concurso, ya que puede influir en el coste final de la operación y, por ende, puede dar lugar a que los posibles adquirentes desistan en su interés por materializar la compra. De modo que, si el juez mercantil establece que la operación constituye una sucesión de empresas, el ámbito de responsabilidad del nuevo adquirente será mucho más amplio que en el caso de ventas de bienes individuales ${ }^{8}$ y si existe sucesión, dicha responsabilidad debe incluir los créditos que puedan ostentar los trabajadores contra la empresa concursada, ya sea por salarios, indemnizaciones o, incluso, deudas comprendidas en el ámbito de la Seguridad Social.

En este punto, adquiere singular relevancia la calificación que el juez mercantil haga de la operación de venta. De hecho, se han dictado numerosas resoluciones por las distintas Salas de lo Social que sostuvieron que el orden jurisdiccional social quedaba vinculado por la referida calificación?. Desde luego, el tema no es baladí, pues si se admitiese la existencia del efecto positivo de la cosa juzgada, la cuestión quedaría, exclusivamente, en manos de la jurisdicción civil.

El Tribunal Supremo, sin embargo, niega cualquier posible vinculación respecto al pronunciamiento del juez mercantil con contundentes argumentos, que pivotan, fundamentalmente, sobre la imposibilidad de aplicar el efecto positivo de la cosa juzgada a quienes no ostentan legitimación para formar parte en el proceso concursal -los trabajadores-.

Aunque podría argumentarse que el planteamiento del Alto Tribunal pueda afectar, en cierta medida, a la seguridad jurídica, especialmente, desde la perspectiva de la adquirente, sin embargo comparto su razonamiento, ya que es cierto que no concurriría la triple identidad que se exige para que se desplieguen los efectos que son propios del instituto que regula el artículo 224.4 de la Ley de Enjuiciamiento Civil ${ }^{10}$.

Además de lo anterior, considero que, al menos durante la vigencia de la legislación aplicable al caso, la resolución que dictaba el juez del concurso en relación la adjudicación de la unidad productiva no producía, ningún efecto fuera del concurso. Se trataba de un pronunciamiento puramente prejudicial, que era necesario para la resolución de la operación de adjudicación, pero que, de conformidad con lo dispuesto en el anterior artículo 9 LC, no producía efectos fuera del concurso,

de convenio y en la de liquidación. Vid. PULGAR EZQUERRA, J. "Las soluciones al concurso de acreedores: el convenio y la liquidación”, en GARCÍA VILLAVERDE, R., ALONSO UREA, A. y PULGAR EZQUERRA, J. (Dirs.), Derecho Concursal. Estudio sistemático de la Ley 22/2003 y de la Ley 8/2003, para la reforma concursal, Madrid, Dilex, 2003, ISBN 139788488910462 , p. 485 y ROJO BELTRÁN, E. y MERCADER UGUINA, J. “Comentario al art. 149”, en ROJO FERNÁNDEZ RÍO, A.J. y BELTRÁN SÁNCHEZ, E.M., Comentarios de la Ley Concursal, Madrid, Civitas/Thomson, 1a ed., 2004, ISBN 84-470-2321-4, p. 2387.

${ }^{6}$ Los actos de disposición patrimonial suelen autorizarse por el juez concursal cuando suponen un aumento de liquidez de la empresa, aun cuando impliquen modificaciones en el activo. Con mayor amplitud, vid. SERRA RODRÍGUEZ, A., "Consideraciones en torno al concepto interés del concurso", Revista Aranzadi de derecho patrimonial, Cizur Menor, Aranzadi, núm. 30/2013, parte artículos, ISNN 1139-7179, pp. 63-93 y GARCÍA-PERROTE ESCARTÍN, I., "Comentario al art. 61”, en ROJO FERNÁNDEZ RÍO, A.J., y BELTRÁN SÁNCHEZ, E.M., Comentarios de..., op. cit., p. 673.

${ }^{7}$ PULGAR EZQUERRA, J. "Las soluciones al concurso de acreedores:...", op. cit., p. 485.

${ }^{8}$ Vid. en este sentido, PULGAR EZQUERRA, J., "Ley 17/2014 de medidas urgentes en materia de refinanciación y reestructuración de deuda empresarial y Real Decreto-Ley 11/2014 de reformas urgentes en materia concursal: nuevos paradigmas", Madrid, Diario La Ley, Wolters Kluwer, núm. 8391, 2014, ISSN 1989-6913, ap. 2.B). También, en este sentido, TUSET DEL PINO, P., "Los efectos derivados de la sucesión de empresa en las adjudicaciones acordadas por el juez mercantil dentro del concurso", Revista de información laboral, Valladolid, Lex Nova, núm. 12, 2015, parte Art. Doctrinal, BIB 2015 18181.

${ }^{9}$ Por todas, destaca la STSJ del País Vasco, de 18 de marzo de 2014 (Ro 382/2014).

${ }^{10}$ Ley 1/2000, de 7 de enero, de Enjuiciamiento Civil. BOE núm. 7, de 8 de enero de 2020. 
por lo que no era posible considerar que esta solución afectase o condicionase la seguridad jurídica. Cuestión distinta era que pudieran verse afectados los concretos intereses económicos de la adquirente, pero este hecho no condicionaba la seguridad jurídica en sí misma.

Tras la entrada en vigor del nuevo Texto Refundido de la Ley Concursal ${ }^{11}$-en adelante, TRLC-, la cuestión ha adquirido un matiz diferente, dadas las modificaciones introducidas en la materia, singularmente, respecto a la atribución de competencia al juez del concurso de todas las cuestiones relativas a la existencia de una sucesión de empresa (art. 221.2 TRLC).

Por ello, me planteo si, en la actualidad, la referida doctrina legal puede entenderse superada como consecuencia del cambio legal que trata de sustraer una competencia que correspondía a la jurisdicción social y que, además, había sido declarada, de forma constante por la jurisprudencia, desde el dictado de la STS de 29 de octubre 2014 (Ro 1573/2013, Sala de lo Social). Mi conclusión al respecto, es que el legislador únicamente ha querido regular la competencia dentro del ámbito del concurso, dejando claro que este órgano debe pronunciarse siempre sobre esa cuestión, a fin de poder luego delimitar el concreto ámbito de responsabilidad de la nueva adquirente ${ }^{12}$, pues al margen de la norma concursal, no se ha producido una correlativa modificación de las normas de atribución de competencia contenidas en la Ley Orgánica del Poder Judicial ${ }^{13}$ o en la Ley Reguladora de la Jurisdicción Social ${ }^{14}$.

La misma duda me suscita la cuestión relativa al ámbito de la responsabilidad solidaria de la adquirente. En la actualidad, el artículo 224.3 TRLC establece una regla particular para los créditos laborales y de Seguridad Social, al ligar la responsabilidad solidaria, únicamente, "a los trabajadores de esa unidad productiva en cuyos contratos quede subrogado el adquirente".

Parece que el legislador concursal ha querido fijar que la responsabilidad solidaria derivada de la sucesión está ligada, exclusivamente, a la plantilla de la unidad productiva que es objeto de subrogación. Por tanto, esto excluiría los créditos de trabajadores con contrato laboral extinguido, ya que, lógicamente, no forman parte del deber de subrogación.

Como se observa, la norma introduce una clara modificación en el sistema legal vigente. La finalidad perseguida por el legislador parece clara, pues trata de agilizar las ventas de unidades productivas, facilitando la continuidad de la parte de la empresa que todavía puede seguir funcionando dentro del mercado. Esta finalidad resulta loable, sobre todo en el momento en el que se dicta, esto es, en plena crisis económica derivada de la pandemia sanitaria por COVID19, que, probablemente, dará lugar a una importante crisis empresarial.

Ahora bien, con ello, se modifica íntegramente la asentada doctrina legal de la Sala Cuarta que la sentencia comentada aplica. Esto es, la doctrina unificada derivada de las sentencias del Tribunal Supremo, de 15 de julio de 2003 (Ro 3442/2001 y Ro 1973/2002, Sala de lo Social), de 4 de octubre de 2003 (Ro 585/2003, Sala de lo Social) y de 30 de noviembre de 2016 (Ro 825/2015, Sala de lo Social). De acuerdo con este cuerpo jurisprudencial, resulta clara la responsabilidad solidaria de las empresas cedente y cesionaria durante los tres años posteriores a la sucesión. Esta responsabilidad comprende las obligaciones laborales nacidas antes de la transmisión, dentro de las que deben entenderse incluidas aquellas que deriven de la eventual declaración de improcedencia de un despido anterior a la transmisión y que no hubieren sido satisfechas. Por tanto, el empresario adquirente queda subrogado en los derechos y obligaciones laborales y de Seguridad Social del

\footnotetext{
${ }^{11}$ Real Decreto Legislativo 1/2020, de 5 de mayo, por el que se aprueba el Texto Refundido de la Ley Concursal. BOE núm. 127, de 7 de mayo.

${ }^{12}$ Vid., GÓMEZ ARBÓS, J., "Los procedimientos concursales en materia de subrogación en relación con la aprobación del Texto Refundido de la Ley Concursal”, Revista Española de Derecho del Trabajo, Cizur Menor, Aranzadi, núm. 236/2020, BIB 2020\36984, p. 51.

${ }^{13}$ Ley Orgánica 6/1985, de 1 de julio, del Poder Judicial. BOE núm. 157, de 2 de julio de 1985.

${ }^{14}$ Ley 36/2011, de 10 de octubre, reguladora de la Jurisdicción Social. BOE núm. 245, de 11 de octubre de 2011.
} 
anterior, en los términos expresamente previstos en la ley, lo que incluye las deudas derivadas de contratos ya extinguidos.

La conclusión que se expresa en la sentencia comentada es totalmente acorde con el sistema legislativo aplicable al caso, pues hay que tener en cuenta que, dentro de las obligaciones y garantías propias de la sucesión es obligado distinguir la obligación de subrogar al personal afectado de la responsabilidad solidaria por deudas pendientes.

La normativa laboral reconoce a los trabajadores una garantía de permanencia en la empresa en los casos de cambio de titularidad, que actúa como elemento neutralizador de la posible extinción de la relación laboral. Ahora bien, esta garantía se proyecta, de forma exclusiva, sobre aquellos que ostenten un contrato laboral que esté vivo al tiempo de la transmisión.

Por su parte, la responsabilidad solidaria de la nueva empresa comprende todos aquellos créditos laborales que, habiendo nacido antes del negocio traslativo, no hayan sido satisfechos. Esta responsabilidad se extiende a los contratos de la plantilla de la unidad que haya sido objeto de transmisión. Por tanto, están incluidos todos los trabajadores y no solo a los que hayan sido subrogados. Se trata de una diferencia fundamental entre el deber de subrogación y la responsabilidad solidaria. Mientras el primero solo afecta a las relaciones laborales vivas, la segunda, comprende todos los contratos ligados a la unidad transmitida, lo que incluye los créditos derivados de contratos que ya se hubieran extinguido al tiempo de la transmisión.

El estado actual de la cuestión no debería verse alterado como consecuencia de las modificaciones introducidas en la normativa concursal tras la promulgación del TRLC, pues no es admisible que un instrumento legislativo - Real Decreto Legislativo-, que está sujeto al concreto mandato contenido en la delegación normativa, introduzca cambios en el sistema legal vigente, que exceden de las meras aclaraciones o colmado de lagunas que admite la jurisprudencia constitucional ${ }^{15}$.

La nueva regulación cambia completamente las previsiones concursales en materia de sucesión de empresa, introduciendo un régimen especial propio, que la anterior normativa no preveía. Por ello, considero que puede haber incurrido en ultra vires, por lo que, hasta que no se dicte una norma, a través de un instrumento legal hábil para ello, debería mantenerse la vigente interpretación jurisprudencial del artículo 44.3 TRLET.

\section{Bibliografía}

GARCÍA-PERROTE ESCARTÍN, I., "Comentario al art. 61", en ROJO FERNÁNDEZ RÍO, A.J., y BELTRÁN SÁNCHEZ, E.M., Comentarios de la Ley Concursal, Madrid, Civitas/ Thomson, $1^{\text {a }}$ ed., 2004, ISBN 84-470-2321-4, pp. 673.

GÓMEZ ARBÓS, J., "Los procedimientos concursales en materia de subrogación en relación con la aprobación del Texto Refundido de la Ley Concursal", Revista Española de Derecho del Trabajo, Cizur Menor, Aranzadi, núm. 236/2020, BIB 2020\36984, pp. 41-67.

GONZÁLEZ BILBAO, E., GONZÁLEZ BILBAO, E., "Identificación de los “intereses concurrentes" y del "interés del concurso" en la nueva Ley concursal”, en AAVV, Estudios sobre la Ley concursal: libro homenaje a Manuel Olivenza, Vol. 1 (Escritos sobre don Manuel Olivenza Ruiz, derecho concursal, aspectos generales, antecedentes históricos, derecho comparado, derecho uniforme, derecho europeo, derecho internacional privado, la declaración de concurso), Vol I, Madrid, Marcial Pons, 2005, ISBN 84-9768-178-9, pp. 293-314.

$\overline{{ }^{15} \text { STC 22/1981, de } 2}$ de julio [RTC 1981/22]. 
PULGAR EZQUERRA, J. "Las soluciones al concurso de acreedores: el convenio y la liquidación”, en GARCÍA VILLAVERDE, R., ALONSO UREA, A. y PULGAR EZQUERRA, J. (Dirs.), Derecho Concursal. Estudio sistemático de la Ley 22/2003 y de la Ley 8/2003, para la reforma concursal, Madrid, Dilex, 2003, ISBN 13 9788488910462, p. 435-503.

PULGAR EZQUERRA, J., "Ley 17/2014 de medidas urgentes en materia de refinanciación y reestructuración de deuda empresarial y Real Decreto-Ley 11/2014 de reformas urgentes en materia concursal: nuevos paradigmas", Madrid, Diario La Ley, núm. 8391, 2014, ISSN 19896913.

ROJO BELTRÁN, E. y MERCADER UGUINA, J. “Comentario al art. 149”, en ROJO FERNÁNDEZ RÍO, A.J., y BELTRÁN SÁNCHEZ, E.M., Comentarios de la Ley Concursal, Madrid, Civitas/Thomson, $1^{\text {a }}$ ed., 2004, ISBN 84-470-2321-4, p. 2378-2395.

SERRA RODRÍGUEZ, A., "Consideraciones en torno al concepto interés del concurso", Revista Aranzadi de derecho patrimonial, Cizur Menor, Aranzadi, núm. 30/2013, parte artículos, ISNN 1139-7179, pp. 63-93.

TUSET DEL PINO, P., "Los efectos derivados de la sucesión de empresa en las adjudicaciones acordadas por el juez mercantil dentro del concurso", Revista de información laboral, Valladolid, Lex Nova, núm. 12, 2015, parte Art. Doctrinal, BIB 2015\18181, pp. 21-42. 